\title{
O território sob o "Efeito Modernizador": a face perversa do desenvolvimento
} The territory under the "Modernizing Effect": the perverse face of the development Le territoire sous "l'Effet Modernisem": la misage méchant du développement El territorio bajo el "Efecto Modernizador": el lado perverso del desarrollo

\author{
Mirlei Fachini Vicente Pereira*
}

Recebido em 25/5/2005; revisado e aprovado em 21/10/2005; aceito em 22/4/2006.

\begin{abstract}
Resumo: As políticas atuais de desenvolvimento territorial às vezes se atrelam, de forma interesseira, ao uso de recursos locais e à implementação de projetos específicos de agentes determinados. Este fenômeno caracteriza o que estamos aqui denominando de "efeito modernizador", fruto das práticas de alguns agentes para tornar o território viável às suas pretensões particulares. Estas práticas acabam por difundir idéias de desenvolvimento e modernização que não se realizam de forma igualitária no lugar.

Palavras-chave: Território; desenvolvimento; “Efeito Modernizador".

Abstract: The current territorial development policies sometimes have a particular relationship, of interest, to in local resources use and to the implantation of certain specific projects. These policies, we denominate "modernizing effect", a product of the some agents to turn the viable territory to their pretensions. These practices result in the diffusing of development ideas and modernization, but they do not occur on equal terms at the place.

Key words: Territory; development; "Modernizing Effect".

Résumé: Les politiques actuelles de développement territorial sont parfois rattachées, de manière intéressée, à l'utilisation des ressources locales et à l'exécution de projets spécifiques d'agents déterminés. Ce phénomène caractérise ce qui est appelé ici de: « effet modernisateur », résultat des pratiques de quelques agents pour rendre possible leurs prétentions particulières. Ces pratiques finissent par propager des idées de développement et de modernisation qui ne se réalisent pas de forme égalitaire dans le local.

Mots-clé : Territoire; développement; « Effet modernisateur ».

Resumen: Las políticas actuales de desarrollo territorial a veces se abocan, de forma interesada, al uso de recursos locales y en la implementación de proyectos específicos de agentes determinados. Este fenómeno caracteriza lo que estamos aquí denominando de "efecto modernizador", fruto de las prácticas de algunos agentes para tornar el territorio viable a sus pretensiones particulares. Estas prácticas acaban por difundir ideas de desarrollo y modernización que no se realizan de forma igualitaria en el lugar.

Palabras clave: Territorio; desarrollo; “Efecto Modernizador".
\end{abstract}

\section{Entre valor e "desvalor": Território - idéias de desenvolvimento e racionalidades de uso}

O território, entendido aqui como o espaço socialmente usado, é o locus onde são produzidas as ações dos homens, das empresas, dos Estados e demais instituições sociais, ou seja - o território pode ser compreendido como sinônimo de espaço geográfico, espaço esse resultante das práticas de todos os agentes, que envolve todas as ações e todos os interesses sociais (SANTOS et. al., 2000).

No atual período histórico, os territórios se apresentam de uma forma integrada, própria do processo de globalização vigente, o que indica uma complementaridade e interdependência funcional dos lugares, sobretudo no que tange às estratégias de mercado e mesmo da organização do território para o seu funcionamento ${ }^{1}$. Ao mesmo tempo, o território também possui um caráter fragmentário, visto que o espaço geográfico apresenta diferentes densidades materiais, de uso e valores também distintos. É assim que os lugares se diferenciam, segundo suas lógicas de funcionamento e suas diferentes inserções no processo de uso econômico do território.

Desta forma, poderíamos pensar que os territórios, desdobrados em distintos subespaços - regiões e lugares, são, relativamente, mais ou menos desenvolvidos, mais ou menos modernos e valorizados, levando em conta suas diferentes lógicas de uso e de

\footnotetext{
* Geógrafo, aluno do doutorado no Programa de Pós-Graduação em Geografia, Universidade Estadual Paulista (UNESP) Campus Rio Claro. Bolsita CNPq, Brasil. (mirleipereira@yahoo.com.br).

Este trabalho resulta, com algumas modificações, da comunicação apresentada pelo autor no Eixo “Desenvolvimento Territorial", durante o V Seminário de Pós-Graduação em Geografia da UNESP, realizado em outubro de 2005, em Rio Claro-SP.
} 
apropriação para o trabalho, que, hoje, mais do que nunca, se renovam de forma frenética. Neste caso, que seria um território moderno e desenvolvido? De que modernização e desenvolvimento se tratam? Em outros termos e trazendo o debate para o nosso país, quais são os conteúdos e usos modernos e desenvolvidos do território brasileiro? Quais conseqüências esta modernização e desenvolvimento acarretam para a sociedade e o território como um todo?

\section{As idéias de modernização e de desenvolvimento: projetos das empresas, projetos dos lugares}

A lógica atual de (re)valorização e (re)desenvolvimento territorial leva em conta a idéia de recursos e de projetos. Assim, as políticas de desenvolvimento territorial se atrelam, na maioria das vezes de forma interesseira, ao uso de recursos locais e à ação de projetos específicos de determinados agentes socioterritoriais que renovam objetos e ações para um novo uso produtivo dos lugares.

A idéia de projeto envolve, diretamente, as noções de plano e intenção. O plano, como delineamento de objetivos, interage com a intenção, que é um propósito, uma vontade determinada. Assim, nos dias atuais, o desenvolvimento e modernização territoriais estão, em grande parte, atrelados a uma ligação dos lugares aos projetos das grandes empresas. Estas, por sua vez, se encontram no mais das vezes coadunadas pelo poder público em suas diferentes escalas de ação, quando não de forma ilícita já tornada prática comum entre empresas e governantes em distintos países.

A intenção das grandes empresas em investir é seletiva, e ela acaba por eleger os lugares que se mostram mais favoráveis, ou seja, aqueles que apresentam as condições ideais e reais (ou em via de realização), e que desta forma satisfaçam as suas necessidades. Podemos, de forma dialética, compreender os interesses das empresas e também os interesses que os lugares possuem em atraí-las. Este último, em verdade, constitui não o interesse do lugar como um todo, mas apenas a vontade de alguns, visto que as benesses do acontecimento se restringem ao alcance de um seleto grupo de agentes. Caberia assim distinguir, de forma complementar, que tanto os territórios e lugares, quanto as grandes empresas, utilizam-se de projetos para o alcance de seus objetivos.

Comecemos pelos projetos das grandes empresas. A idéia e prática atual destes agentes hegemônicos da economia são, no contexto do atual capitalismo globalizado, encontrar o lugar (no conjunto de um território nacional) que mais satisfaça os seus interesses produtivos, levando em conta, desta forma, o menor esforço por parte da empresa em adicionar ao lugar escolhido os elementos técnicos necessários para a implementação de seu projeto. Ou seja, a questão da localização dos empreendimentos produtivos há muito tempo resulta das vantagens comparativas e concorrenciais, que envolvem tanto a natureza da atividade produtiva como a natureza do local onde a atividade é (ou será) implantada (BENKO, 1996).

Nesse sentido, poderíamos dizer que o projeto das grandes empresas, para o seu próprio benefício e desenvolvimento, possui uma dimensão territorial de importância extrema, que somada a dimensões políticas e econômicas, entre outras, se torna elemento estratégico para o êxito do seu projeto.

Por outro lado, os lugares também possuem projetos. Projetos múltiplos que acolhem distintas racionalidades de dimensões e propósitos muito diferenciados daqueles das empresas. Num primeiro momento conviria falar numa idéia desenfreada de "desenvolvimento a qualquer custo", que tem promovido, caberia dizer, uma verdadeira "guerra entre lugares" pela disputa de empreendimentos com grande aporte de recursos (tal como a instalação de empresas multinacionais), na idéia de que são estes empreendimentos os únicos capazes de renovar a dinâmica econômico-produtiva de municípios e mesmo de regiões inteiras. Detalhe que, aqui, na maioria das vezes, a idéia de (re)dinamizar/(re)desenvolver a economia e o território é acolhida de forma imediata, sem qualquer preocupação de fundo ideológico/político por parte dos governantes, principalmente na escala do poder público municipal. A normalmente denominada "guerra fiscal", fenômeno comum no território brasileiro no fim do século passado e 
início do atual é exemplo nítido deste processo (CATAIA, 2003).

Neste caso, e quando o projeto de "desenvolvimento" é empreendido desta forma, o que resta não é outra coisa do que o casamento das intenções das grandes empresas com a vontade insaciável de atração destas pelos agentes políticos de determinados lugares. No entanto, se são duas as aspirações, dois planos/projetos que se interpenetram (o das empresas e o dos lugares), a realidade do território usado denuncia que apenas um projeto é vencedor, somente um logra êxito.

$\mathrm{Na}$ ânsia por um "desenvolvimento territorial fácil", os lugares acabam por entregar todos os seus recursos territoriais, e nesta ocasião, acabam por tornar-se "presa fácil" das grandes empresas que só aspiram, e o fazem da forma mais pragmática, o alcance dos seus objetivos de mercado.

A atual lógica de uso do território pelas grandes empresas, em se tratando do caso brasileiro, acaba praticamente por negar toda e qualquer idéia de um projeto autônomo de desenvolvimento, ou seja, de um desenvolvimento verdadeiramente a partir do lugar e para os anseios do lugar. O projeto vencedor é assim, no mais das vezes, aquele que favorece a acumulação de alguns poucos agentes; e os projetos dos lugares, que por vezes ate se acreditam bem orientados, revelam-se, na verdade, uma promessa negada. O processo fica claro quando demonstramos a idéia de recursos, evidenciando que a pretensão de construir um projeto autônomo é normalmente substituída por um discurso de uso de "recursos fáceis", porém insustentáveis.

Mas quais são estes recursos territoriais? Como se dão, nos lugares, as suas formas de entrega facilitada ao projeto das grandes empresas? As custas de quê os projetos das grandes empresas logram êxito e como encontrar novos projetos que verdadeiramente expressem os anseios de desenvolvimento autônomo dos lugares?

\section{Desenvolvimento por quais vias? $\mathrm{O}$ problema do uso dos recursos}

Como temos destacado, podemos reconhecer, de forma complementar à idéia de projetos, a presença e a força da idéia de re- cursos nas políticas de desenvolvimento territorial. Não pretendemos fazer neste trabalho uma análise de recursos territoriais ou mesmo de "territórios de recursos" baseada na leitura econômica do território (BENKO \& PECQUER, 2001). Nossa idéia aqui é fundamentada no uso do território, ou melhor, em todas as experiências possíveis de uso territorial, e quando o uso (total) e o território (como um todo) é levado em conta, o conceito de recurso deve aparecer de duas formas, ambas apresentando na maioria das vezes o mesmo significado para o território.

Numa primeira idéia, os lugares são eleitos como verdadeiros recursos pelas grandes empresas, porque eles contêm os meios para auxiliar e mesmo efetivar as suas ações, os seus interesses. Assim, as grandes empresas, antes de instalar-se, acirram diferentes localidades e empreendem esforços para que, aquele lugar que fora finalmente eleito para a instalação, lhe conceda uma série de incentivos que nada mais são do que recursos disponíveis no território.

No Brasil atual, estes recursos territoriais entregues às grandes empresas se apresentam na forma de isenção total ou parcial de impostos, doação de terrenos e demais infraestruturas territoriais (facilidades de acesso e de distribuição do que é produzido, informação, etc.), sem contar as condições de mão-de-obra barata encontradas praticamente em todo o território nacional. Cada um destes itens se diferencia em importância para determinado tipo de empresa ou atividade. Assim, as grandes empresas acabam, nas palavras de Milton Santos (2000), fazendo uso do território como mais um recurso a ser explorado. Exploração esta que não se reverte em ganhos para o território como um todo.

Contraditoriamente, e ao mesmo tempo, as grandes empresas também são vistas como recurso para o desenvolvimento dos lugares, e acabam figurando, quando "conquistadas", como verdadeiros trunfos. Para isto, basta reconhecer no território, e o território brasileiro é exemplo típico deste processo, o que significa a vinda, ou melhor, a acirrada conquista de uma grande empresa, principalmente quando se trata das grandes empresas estrangeiras. Neste caso, e numa leitura enviesada e míope por parte 
de alguns, as grandes empresas atuariam como meio, ou seja, como recurso estratégico para que os lugares vençam as dificuldades comuns do período (principalmente o desemprego), alcançando assim o almejado "desenvolvimento".

No entanto, a idéia de desenvolvimento e de modernidade que comumente se instala a partir da presença destes novos vetores no território (uma nova empresa), ou ainda, somente as aspirações veiculadas pela mídia no trabalho nada difícil de legitimação dos projetos das grandes empresas, já confere uma legitimidade a priori dos lugares considerados "atrasados" ou "marginais". O que ocorre neste caso, com a entrega dos recursos territoriais aos projetos das grandes empresas, ou mesmo a tomada do lugar/território como recurso pelas mesmas, é na verdade o que estamos denominando de "efeito modernizador", visto que, aparentemente, os lugares lucrariam com o simples fato da instalação destas novas empresas e das novas infraestruturas territoriais que normalmente as acompanham ${ }^{2}$.

\section{O efeito modernizador e suas conseqüências territoriais}

Esta renovação do conteúdo material do território confere aos lugares a emergência do que estamos chamando de "efeito modernizador". Este seria todo o conteúdo territorial (objetos e ações) que se impõe como novo, e que, ganhando localmente um caráter de proeminência em relação aos demais, acaba por centralizar toda a atenção e ação dos agentes públicos. Por isso se tratar apenas de uma modernização aparente, porque se dá de forma centralizada e não repercute em ganhos e melhorias para todos os que habitam o lugar. Tirando proveito político da situação de renovação territorial, e invertendo e distorcendo as atenções da sociedade, o poder público (nas suas diferentes escalas territoriais), apoiado na legitimidade aparente dos projetos de modernização e desenvolvimento, se volta para a razão das ações privadas, promovendo desta forma um uso corporativo do território.

Esta situação, muito cara à idéia de desenvolvimento fundada a partir da entrega dos recursos territoriais, e mesmo valeria di- zer, da "entrega do território" às grandes empresas, é assim um desenvolvimento e uma modernização concentradores. Tratase na verdade de um efeito de modernização que mascara e falsifica, seleciona e exclui. É o tipo de desenvolvimento territorial pregado pelo poder público descompromissado com a sociedade, e próprio dos macroatores econômicos do período que só têm olhos para si. É o impedimento da ação, é a imposição de um projeto único, que também se revela como o pensamento e a estruturação de um modelo de desenvolvimento "inevitável".

Conviria destacar um novo dado do período que nos permite mais uma vez deixar de lado a velha idéia de determinismo do meio (ou determinismo ambiental), para nos atermos com atenção aos processos que evidenciam a constituição de verdadeiros "espaços determinados", onde imperam razões alheias à sua ordem pretérita, determinação e racionalização estas que são próprias do processo de alienação territorial comum do presente período (SANTOS \& SILVEIRA, 2001).

É justamente disso que se trata - uma alienação e uma inversão de valores no que tange ao significado do público e do privado. O poder público governa e remete recursos públicos para os projetos privados de grandes empresas, na idéia de que estas, a partir de suas ações no território seriam capazes de promover algo como "sinergias" e "externalidades" que se reverteriam em desenvolvimento econômico e social para o lugar como um todo. Recursos públicos, socialmente constituídos no lugar, financiando projetos privados, na expectativa de que um dia estes sejam capazes de produzir novos recursos para uso social.

Assim, o território parece alienar-se, deixa-se levar pelos interesses de agentes estranhos à sua própria natureza e lógica internas, e busca, a partir destes, obter um "desenvolvimento" que, na maioria das vezes, se reverte em mais problemas de ordem social para o lugar como um todo.

Este tipo de desenvolvimento territorial, determinado e determinante, é o futuro preparado por alguns, e o território corporativo e ideal que é também produzido para alguns seletos agentes. É a razão própria de uma lógica vertical ${ }^{3}$ de uso do 
território e é também, ao mesmo tempo, a negação das oportunidades distintas de desenvolvimento para os outros. "Observamos assim que, na verticalidade acontecem tanto o impedimento da ação inovadora e criadora, da verdadeira práxis, quanto a reafirmação da dimensão territorial da alienação" (RIBEIRO, 2003, p.35).

Como o discurso dos agentes hegemônico da economia e da política se impõe com maior força, (re)criando necessidades e razões no território, parece não restar outra estratégia de "desenvolvimento" que não se atrele a uma ligação com os projetos e interesses das grandes empresas. Daí o esforço sem fim das políticas de "desenvolvimento territorial" para, de uma forma também competitiva, dotar o território com as infraestruturas diversas e as normas territoriais (ex. isenção de impostos), tornando o território viável à ação dos agentes hegemônicos.

Assim, a forma como os projetos das grandes empresas são legitimados no conjunto da sociedade, e também a maneira como os planos de desenvolvimento territorial são implantados pelo poder público, são exemplos de manifestações do pensamento único (SANTOS, 2000) que se impõe de forma despótica em todas as esferas da vida social, e, portanto, nas políticas de condução do uso do território.

\section{A pertinência dos projetos dos lugares para a necessária reconstrução do território}

Como os lugares poderão encontrar, nas circunstâncias do mundo atual, possibilidades de desenvolvimento autônomas? Será possível pensarmos caminhos alternativos, que remetam a outras formas e outras políticas para a elaboração de projetos comuns que atendam genuinamente aos interesses de todos no lugar?

Cabe aqui analisarmos quanto das denominadas políticas de desenvolvimento territorial e de desenvolvimento local realmente estão assentadas em propostas que buscam um desenvolvimento autônomo e que garanta a liberdade de iniciativas, além de princípios éticos e políticos para a construção e definição de estratégias de desenvolvimento que atendam de forma eficaz as particularidades de cada lugar e os anseios das coletividades territorialmente enraizadas. Será isto possível a partir, somente, de programas de governo ou da ação de grandes empresas em lugares específicos?

Parece-nos estarmos vivendo um período de banalização da idéia de desenvolvimento, e também banalização das experiências locais em busca de desenvolvimento verdadeiramente autônomo, como se este fosse facilmente transposto de lugar para lugar, sem maiores implicações. Uma "ideologia desenvolvimentista" também tem promovido a banalização da cultura dos lugares, de suas especificidades históricas e de recursos territoriais e ambientais únicos em nome de experiências falseadas de "desenvolvimento local/territorial" empreendidas sem levar em conta os interesses das sociedades e dos lugares como um todo.

Estes fatos nos levam à necessidade de empreender um esforço de distinção epistemológica entre lugar e local, que se mostra pertinente na discussão do desenvolvimento - "O local pode ser lido como nicho ou alvo de ações desenhadas noutras escalas. Já o lugar abriga, além de conseqüências destas ações, enigmas, carências e projetos do existir. Não se trataria, realmente, de propor uma oposição absoluta entre estas idéias-conceitos, mas de indicar que local e lugar correspondem a sensibilidades analíticas e políticas distintas. O local traz referências à heteronomia, enquanto o lugar é portador de anseios de autonomia. Completando-se, portanto" (RIBEIRO, 2004, p.44).

Assim, nas políticas de desenvolvimento, os lugares necessitam impor-se, necessitam ser olhados, como "projetos comuns dos lugares", fundados em anseios de liberdade e de autonomia, que atendam, de uma forma ou de outra, a totalidade dos agentes comuns do e no lugar, numa base territorial que também seja comum.

Não se trata, de modo algum, da negação dos projetos dos grandes agentes econômicos e da grande produção, nem mesmo de atuar de forma a construir uma postura "xenófoba" dos lugares, mas, da mesma forma como os vetores externos (as ações verticais das grandes empresas) têm imposto aos lugares suas vontades de forma despótica, fazer impor os interesses e demandas para que os projetos (tanto das empresas como 
dos lugares) ocorram a partir de um diálogo profícuo, permitindo desta forma que os lugares não se tornem "presa fácil" das grandes empresas, e que os recursos socialmente constituídos e longamente elaborados no território não se tornem elementos de uma verdadeira "acumulação prévia" que viabiliza a instalação e o funcionamento do projeto hegemônico no território.

Em outras palavras, o território deve deixar de ser usado apenas como recurso pelos agentes hegemônicos. O lugar, leia-se aqui - a sociedade organizada a partir de uma base territorial comum e entorno de interesses comuns, deve impor suas leis e suas vontades para fazer jus a um desenvolvimento, este sim valeria dizer - local e sustentável, e a uma modernização que atenda aos anseios de todos e que não se instale apenas como um "efeito" aparente. O papel do poder público, e de uma verdadeira refundação do Estado e da política, tal como propõe Emir Sader (2003), se mostra extremamente necessário para que esta ação criadora se fortaleça e possa emergir verdadeiramente como práxis.

Exemplos de eventos que poderíamos denominar como verdadeiros aconteceres libertários, ou pelos menos a sua insurgência e potência, afloram nos quatro cantos do mundo e permitem com que os olhamos como forças presentes e efetivas para a invenção de uma nova ordem. É o próprio território, através de seus distintos lugares, solidariedades construídas entre agentes no espaço, que promove a emergência de buscas alternativas ao projeto hegemônico que se pretende único.

Desta forma, podemos observar que "O território não é inerte. Só os atores hegemônicos podem criar e difundir essa fantasia, já que não necessitam, ou não querem reconhecer explicitamente a ação do Outro. Aqueles que precisam construir condições de vida em contextos adversos não podem aderir a essa fantasia, que destrói a compreensão do jogo da política" (RIBEIRO, 2003, p.37).

No Brasil e em todo o mundo, inúmeros casos de cooperativismo e de propostas coletivas e solidárias parecem indicar novos caminhos. De forma mais pontual, poderíamos citar outros exemplos e ações - o sistema escolar dos assentamentos do Movimen- to dos Trabalhadores Sem-Terra (MST), oferecendo uma educação para a autonomia (SADER, 2003, p.320); o movimento das comunidades negras na Colômbia (LEFF, 2002); o de indígenas e camponeses organizados pela busca de seus direitos em toda a América Latina (PORTO-GONÇALVES, 2002); a luta dos seringueiros no Acre, pelo direito de explorar a terra e a floresta, na busca de um desenvolvimento baseado em conhecimentos longamente elaborados no lugar (PORTO-GONÇALVES, 2003); também destacam este caráter de estruturação de uma nova política de condução da vida e do território. Os ativistas do movimento das comunidades negras no Pacífico sul-colombiano, por exemplo, “(...) conceitualizam o território como um espaço para a criação de futuros, para a esperança e a continuação da existência" (LEFF, 2002, p.278), fundando uma nova ótica (e também uma nova ética) de valor para o território, que se baseia na política do lugar e da diferença.

Contraditoriamente, são nestas ações advindas dos "de baixo", dos movimentos populares de toda a ordem e das sociedades localmente organizadas, da ação criadora dos homens comuns no território e não na ação opressora do acontecer hierárquico (SANTOS, 1997, 2005), próprio das ações hegemônicas, dos preceitos interesseiros daqueles que são "externos ao lugar", que podemos encontrar o verdadeiro conteúdo moderno, e por que não, desenvolvido, dos territórios. Esta é a manifestação do movimento que agora se inicia, fundado na idéia de projetos dos lugares, para o necessário reencantamento do mundo e da vida.

\footnotetext{
Notas

${ }^{1}$ Quanto à interdependência dos lugares no mundo globalizado vide - para a economia, François Chesnais (1996); para a produção industrial e da informação, Manuel Castells (1999), entre outros. Exemplos da interdependência funcional dos lugares no território brasileiro podem ser encontrados na obra de Milton Santos e María Laura Silveira (2001).

2 É interessante notarmos como no Brasil atual a conquista de grandes empresas é festejada como um verdadeiro prêmio por prefeitos, vereadores e lideranças políticas locais. Mais do que isso, são produzidos, via mídia, discursos em que os próprios municípios ou regiões (ou seja, o próprio território) é que são "vencedores". Essa é mais uma manifestação e conseqüência do que estamos aqui chamando de "efeito modernizador".
} 
${ }^{3}$ A idéia de verticalidade ou de uso vertical do território foi desenvolvida por Milton Santos $(1997,2005)$ e pode ser compreendida, resumidamente, por aquelas possibilidades de uso e ação territorial que são presididas por agentes externos e distantes, inserindo no conteúdo do território racionalidades alheias aos interesses dos lugares e da sociedade como um todo.

\section{Referências}

BENKO, G. Economia, espaço e globalização na aurora do século XXI. 2.ed. São Paulo: Hucitec, 1999.

BENKO, G. \& PECQUEUR, B. Os recursos do território e os territórios de recursos. Geosul, Florianópolis, v.16, n.32, p.31-50, 2001.

CASTELLS, M. A era da informação. A sociedade em rede. Rio de Janeiro: Paz e Terra, 1999. v.2.

CATAIA, M. A alienação do território - o papel da guerra fiscal no uso, organização e regulação do território brasileiro. In: SOUZA, M. A. A. (org.) Território brasileiro: usos e abusos. Campinas: Edições Territorial, 2003. Cap. 23, p.397-407.

CHESNAIS, F. Mundialização do capital. São Paulo: Xamã, 1996.

LEEF, H. A geopolítica da biodiversidade e do desenvolvimento sustentável: economização do mundo, racionalidade ambiental e reapropriação social da natureza. In: CECEÑA, A. E. \& SADER, E. (Org.) A guerra infinita. Petrópolis: Vozes, 2002. p. 253-288.
PORTO-GONÇALVES, C. W. O latifúndio genético e a r-existência indígeno-campesina. Geographia, Rio de Janeiro, ano IV, n.8, p.39-60, 2002.

Geografando nos varadouros do mundo: da territorialidade seringalista ( $\mathrm{O}$ Seringal) à territorialidade seringueira (A Reserva Extrativista). Brasília: IBAMA, 2003.

RIBEIRO, A. C. T. Lugares dos saberes: diálogos abertos. In: BRANDÃO, M. A. (Org.) Milton Santos e o Brasil. São Paulo: Perseu Abramo, 2004. p.39-49.

Pequena reflexão sobre Categorias da Teoria Crítica do Espaço: Território Usado, Território Praticado. In: SOUZA, M. A. A. (Org.) Território brasileiro: usos e abusos. Campinas: Edições Territorial, 2003. Cap. 1, p.29-40.

SADER, E. A refundação do Estado e da política. In: NOVAES, A. (Org.) A crise do Estado-Nação. Rio de Janeiro: Civilização Brasileira, 2003. p.305-321.

SANTOS, M. A natureza do espaço. Técnica e tempo. Razão e emoção. 2.ed. São Paulo: Hucitec, 1997.

. Da totalidade ao lugar. São Paulo: Edusp, 2005.

Por uma outra globalização: do pensamento único à consciência universal. Rio de Janeiro: Record, 2000.

SANTOS, M. \& SILVEIRA, M. L. O Brasil: território e sociedade no início do século XXI. Rio de Janeiro: Record, 2001.

SANTOS, M. et. al. O papel ativo da geografia: um manifesto. Florianópolis: Laboplan-USP, 2000. 